\title{
Lifestyle and Dietary Factors Associated with Inflammatory Bowel Disease among Jordanian Patients
}

\author{
Tamara R. Qalqili ${ }^{1}$, Yaser M. Rayyan ${ }^{2}$, Reema F. Tayyem ${ }^{1}$
}

1) Department of Nutrition and Food Technology, Faculty of Agriculture, The University of Jordan, Amman;

2) Department of Gastroenterology \& Hepatology, School of Medicine, The University of Jordan, Amman, Jordan

Address for correspondence: Reema F. Tayyem The University of Jordan, Amman 11942, Jordan r.tayyem@ju.edu.jo
Received: 07.10 .2020 Accepted: 15.12.2020

\begin{abstract}
Background \& Aims: Inflammatory bowel diseases (IBD) affect Jordanian adults more than other age groups. Several studies highlight the independent effect of various lifestyle factors on the risk of IBD. Therefore, this study aims to compare the differences between some lifestyle factors among IBD cases and IBD-free controls, while detecting the varying degree of malnutrition in the study sample.

Methods: A case-control study was conducted between November 2018 and December 2019. Three hundred and thirty-five Jordanian adults above the age of 18 years were enrolled in this study. Out of the 335 participants, 185 of them were recently diagnosed with IBD [100 ulcerative colitis (UC) and 85 Crohn's disease (CD)] and 150 IBD-free controls. Sociodemographic characteristics, anthropometric measurements, dietary habits and the degree of malnutrition using the Patient-Generated Subjective Global Assessment (PG-SGA) were collected from all participants.

Results: Body mass index and waist circumference were significantly different in UC patients as compared to controls. Cigarette smoking, work status, duration of sleeping hours, physical activity, number of daily main meals intake, meals skipped daily, number of daily snack meal intake, and fast-food intake were all significantly different when comparing IBD cases to controls. While cigarette smoking ( $\mathrm{OR}=0.52,95 \% \mathrm{CI}$ : $0.29-0.96, \mathrm{p}=0.02)$ and sleep duration hours during working day ( $\mathrm{OR}=0.05,95 \% \mathrm{CI}: 0.01-4.68, \mathrm{p}=0.001)$ ] were found to be protective factors, the increase in daily working hours ( $\mathrm{OR}=22.13,95 \% \mathrm{CI}: 10.35-47.32, \mathrm{p}=0.001)$ was identified as a risk factor for IBD. The degree of moderate and severe malnutrition among patients with IBD was significantly $(\mathrm{p}<0.001)$ higher as compared to controls.

Conclusions: Patients with IBD had lower BMI and physical activity values compared to controls. The number of daily main meals intake, meals skipped daily, number of daily snack meals intake, fast food intake and the degree of malnutrition were significantly different when IBD cases were compared to controls.
\end{abstract}

Key words: inflammatory bowel diseases - ulcerative colitis - Crohn's disease - lifestyle factors - smoking - physical activity - malnutrition.

Abbreviations: BMI: body mass index; CD: Crohn's disease; CI: confidence interval; D: density; HEPA: health-enhancing physical activity; IBD: inflammatory bowel diseases; MET: metabolic equivalent; OR: odds ratio: PA: physical activity; PAR: physical activity 7-day recall; PG-SGA: Patient-Generated Subjective Global Assessment; SFT: skinfold thickness; UC: ulcerative colitis.

\section{INTRODUCTION}

Inflammatory bowel diseases (IBD) is affect the colon as in ulcerative colitis (UC) and/or any part of the gastrointestinal tract as in Crohn's disease (CD) [1]. While UC causes long-lasting inflammation and superficial ulcers of the inner lining layers of the large intestine (colon) and rectum, $\mathrm{CD}$ is characterized by inflammation of the lining of the digestive tract, particularly the ileum, which often spreads with deep ulcers of affected tissues in skipped fashion [2].

Several lifestyle factors have been linked with IBD including smoking, diet, physical activity, and stress. In addition, these factors may play a role in increasing the risk of or protecting against the development of IBD. The relevant risk factors (including smoking, hygiene hypothesis, microorganisms, appendectomy, medication, nutrition, and stress) have all been associated with the pathogenesis of IBD [3]. Many studies have examined the role of physical activity and active lifestyle as potential protective factors in the development of 
IBD $[4,5]$. In a matched-subjects study design (age, gender, geographical location) conducted on $\mathrm{CD}, \mathrm{UC}$, and controls, $\mathrm{Ng}$ et al. [4] found a protective effect of exercise and onset of CD, but none for UC patients. However, Chan et al. [6] found that there was no association between physical activity levels and UC or CD. In addition, within the last three decades, smoking was established as a risk factor in the development of IBD [7]. Smoking is one of the most important and well-characterized environmental risk factors for IBD; however, its pathogenic mechanism is not clear. Further evidence from studies suggest that smoking is a causative agent in CD while it is protective against UC $[8,9]$.

Moreover, additional lifestyle factors, such as stress, have been identified to potentially enhance the risk of developing IBD. In an animal-model study, it was found that stress reduces mucus secretion and increases intestinal permeability of the colon among mice [10]. Furthermore, a study conducted by Bitton et al. [11] documents the association between major life stress factors, anxiety, and depression, and IBD risk.

Nutrition plays a pivotal role in the clinical care of patients with IBD. In broad terms, nutritional therapy can be considered as a supportive or even a primary treatment. Supportive therapy aims to correct malnutrition and micronutrient deficiencies and reverse their metabolic pathological consequences, while also providing advice on specific dietary regimes [12]. A study by Nguyen et al. [13] reveals that the prevalence of malnutrition is greater in $\mathrm{CD}$ and UC patients than in non-IBD patients (6.1\% and $7.2 \%$ versus $1.8 \%, \mathrm{p}<0.0001)$. Additionally, there is an increased likelihood of malnutrition among those with fistulizing $\mathrm{CD}$ and those who have undergone bowel resection. Furthermore, malnutrition is associated with an increase of in-hospital mortality [13].

The incidence of IBD has increased in both developing and developed nations as this could be largely attributed to the change in dietary and lifestyle factors associated with modernization [14]. As the incidence and prevalence of IBD continues to increase, it has developed into an emerging global disease [14]. In Jordan, UC and CD are not rare and occur among all age groups with a peak incidence in the third decade of life [15]. According to the authors' knowledge, no studies have been conducted to investigate the dietary and lifestyle factors associated with IBD and the degree of malnutrition among Jordanians. Therefore, this study aims to compare the differences between specific lifestyle factors among IBD cases and IBD-free controls and to detect the degrees of malnutrition in the study sample.

\section{METHODS}

A case-control study design was used to determine lifestyle and dietary factors associated with IBD and the degree of malnutrition among Jordanian adults. In this study, 352 adult Jordanians were enrolled; 185 patients were recently diagnosed with IBD ( 85 with CD and 100 with UC). Seventeen participants did not meet criteria and were excluded (Fig. 1). Patients were recruited from the following 3 hospitals: University of Jordan Hospital, Zarqa Governmental Hospital, and Al Bashir Hospital. One hundred and fifty IBD-free controls were recruited from the community, which includes the employees and visitors from the University of Jordan Hospital, Zarqa Governmental Hospital, and Al Bashir Hospital, as well as employees working in various companies and organizations. Further, cases and controls in this study were matched based on age and marital status. The inclusion criteria of patients recruited in the study were: being above 18-years old; patients who were recently (within 3 months) diagnosed with IBD; Jordanian nationality; and able to communicate verbally and to sign an informed consent. Participants (from both groups; cases and controls) who suffer from cancers, acute appendicitis, food allergy, food intolerance, infection, primary intestinal lymphoma, intestinal tuberculosis, irritable bowel syndrome, and anal fistulas; pregnant and lactating women; and/or unable to communicate verbally were excluded from the study.

A hospital setting was utilized for data collection. Hospitals that offer services for patients with IBD were chosen to conduct the study. The outpatient department in each hospital was the setting for data collection. The proposal was presented to the Institutional Review Board (IRB) of each hospital to get their ethical approval. Approval from each hospital was gained to ensure that a private room with good physical conditions was available to conduct interviews (The University of Jordan Hospital IRB number was 22/2019-4312; Zarqa Governmental Hospital and Al Basheer Hospital IRB number was 3199). A signed consent was obtained before data collection from each participant. Collected information was treated confidentially in which only the researcher knew patients' names and randomly assigned them a study ID. All tools and instruments (questionnaires and test tubes) used were labeled with patient number.

Face-to-face interview technique was used as a method for data collection and the questionnaires were completed by a trained dietitian. During data collection, patients were asked about their usual and habitual dietary, lifestyle as well as physical activity practices before experiencing IBD symptoms. For this purpose, a three-part package was used for the behavioral data collection portion of this study. This package consists of a personal information sheet and the following three structured questionnaires: Seven-Day Physical Activity Recall (PAR); and Patient-Generated Subjective Global Assessment (PG-SGA).

This sheet consists of questions related to age, gender, marital status, education, employment, anthropometric measurements (current body weight, usual body weight, height, and waist circumferences), family income/month, residency area and house condition, inquiry on smoking history included three status (never, former or current), previous and current health problems, number of main and snack meals during a day, and vitamins supplements.

The number of hours spent in different activity levels was obtained from physical activity recall (PAR), developed by Sallis et al. [16], and then converted into metabolic equivalent (MET). A MET is defined ,as the resting metabolic rate, that is, the amount of oxygen consumed at rest, sitting quietly in a chair, approximately $3.5 \mathrm{ml} \mathrm{O} / \mathrm{kg} / \mathrm{min}(1.2 \mathrm{kcal} / \mathrm{min}$ for a 70-kg person)" [17]. Average MET for moderate activity = 3.3 METs, vigorous activity $=8$, and extreme activity $=10$. The score expressed as MET-min per week was calculated by using this equation: (MET level ${ }^{\star}$ minute of activity ${ }^{\star}$ days per 
week) [18] to transfer into the categorical analysis: inactive, minimally active, and health-enhancing physical activity (HEPA). These categories were scored depending on the standard scoring protocol of the International Physical Activity (PA) Questionnaire (version 2, 2004). The inactive category represents the lowest level of $\mathrm{PA}$, which represents individuals who did not meet the criteria for categories 2 or 3 . Minimally active category includes subjects who reported at least one of the following 3 criteria's; 3 or more days of vigorous activity of at least 20 minutes per day, 5 or more days of moderateintensity activity or walking of at least 30 minutes per day, 5 or more days of any combination of walking, moderate-intensity or vigorous-intensity activities achieving a minimum of at least $600 \mathrm{MET}-\mathrm{min} /$ week. Health-enhancing physical activity active category, which is a more active category, includes any subject who performed vigorous-intensity activities on 3 or more days per week and accumulated at least 1500 Met-min per week or who performed any combination of walking, moderateintensity or vigorous-intensity activities on 5 or more days to achieve a minimum of at least 3000 MET-minutes/week [19].

The subjective global assessment (SGA) is a simple, sensitive tool used to identify nutritional risk. It is widely used in the adult population [20]. The assessment took approximately ten minutes, and the questionnaire includes the following multiplechoice sections: history of weight loss in the past two weeks, changes in dietary intake during the last month (e.g., more or less than usual, mainly solid or liquid foods), nutritional symptoms (e.g., nausea, vomiting, dysgeusia, dysphagia, pain), functional capacity (e.g., normal activity, much time in bed or chair) and metabolic stress (fever). The physical examination was associated with malnutrition signs and symptoms (loss of subcutaneous fat, muscle wasting, edema). For the global assessment categories of the nutritional status in the PatientGenerated Subjective Global Assessment (PG-SGA), patients were assigned to well-nourished ( $A$, at least three sections rated as normal), mildly malnourished (B, at least three sections rated as mild malnutrition), moderately malnourished (C, at least three sections rated as moderate malnutrition) and severely malnourished $(\mathrm{D}$, at least three sections rated as severe malnutrition).

Current body weight, height and waist circumference of participants were measured according to Lee and Nieman [21]. Body mass index (BMI) was calculated as the ratio of weight in kilograms to the square of height in meters. The skinfold thickness (SFT) measurements were taken for the triceps muscle at the midpoint between the olecranon process of the elbow and the acromial process of the scapula in the back of the upper left arm for right-handed people or the right hand left-handed people [21]. Harpenden skinfold thickness caliper (USA, model SFC-1000) was used to measure SFT to the nearest $0.2 \mathrm{~mm}$ [22]. The Jackson and Pollock equation was used to calculate body density (D) in male and female. Male: $1.10938-(0.0008267 \times$ SFT in $\mathrm{mm})+(0.0000016 \times$ SFT in mm squared $)-(0.0002574 \times$ age $)$ [23]. Female: $1.0994921-$ $(0.0009929 \times \mathrm{SFT}$ in $\mathrm{mm})+(0.0000023 \times \mathrm{SFT}$ in $\mathrm{mm}$ squared $)$ - $(0.0001392 \times$ age $)$ [24]. Body fat $\%$ was calculated using the following equation: Body fat $\%=[(4.95 / D)-4.5] \times 100$ [25]

All statistical analyses were conducted using SPSS version 22.0 (IBM SPSS Statistics for Windows, IBM Corporation). The decision to enroll the following number of cases in this study (100 UC and $85 \mathrm{CD}$ ), was determined based on literature reviews and previously conducted studies, as the prevalence rate of IBD cases in Jordan was not available at the start of this study. According to Chan et al. [6], 75 participants are enough to calculate odd ratios for the risk for developing the disease, thus we decided to enroll well over that estimated number of participants in our study to ensure an adequate sample size. In addition, only eligible patients who were diagnosed between November 2018 and December 2019 timeframe were enrolled in the study. Descriptive analyses were conducted to examine the frequency of different variables. Chi-square test was used to detect the statistical differences among categorical variables. One-way ANOVA test coupled with Least Significant Difference (LSD) test was used to find the difference between continuous variables of cases (UC and CD) and controls. Data was presented as mean \pm standard deviation (SD). The significance level was set at $\mathrm{p}<0.05$. The odds ratios (OR) and 95\% confidence intervals (CI) obtained from multivariable logistic regression models were taken as the measures of predictors of IBD risk. OR was adjusted for age, gender, marital status, education level, work status, monthly income, physical activity, smoking, family history.

\section{RESULTS}

Three hundred and thirty-five Jordanian adults between the age of 18-68 years were recruited. Of the 335 participants enrolled in this study, 185 of them were recently diagnosed with IBD (100 UC, 85 CD) and 150 IBD-free controls (Fig. 1). The percentage of gender distribution was different between the three groups. Table I shows the results of socio-demographic and health characteristics.

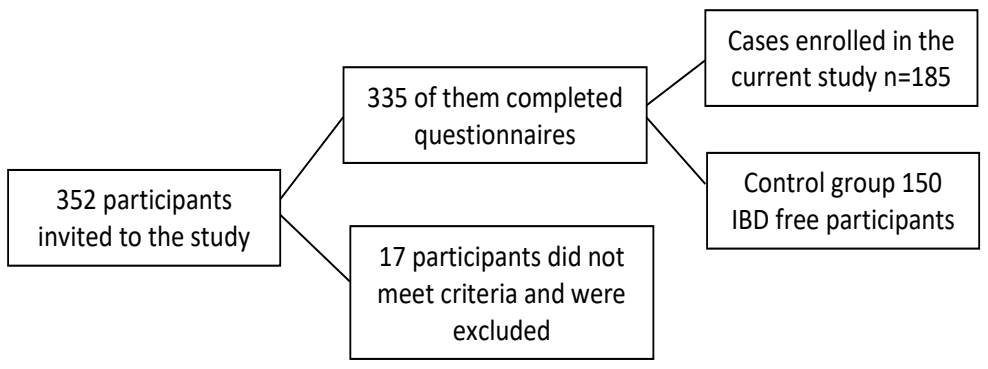

Fig. 1. The participants' selection for the study. 
Table I. Socio-demographic and lifestyle characteristics among the study participants ( $\mathrm{n}=335)$.

\begin{tabular}{|c|c|c|c|c|}
\hline Variables & Control $(\mathrm{n}=150) \mathrm{N}(\%)$ & $\mathrm{UC}(\mathrm{n}=100) \mathrm{N}(\%)$ & $\mathrm{CD}(\mathrm{n}=85) \mathrm{N}(\%)$ & $\mathrm{p}$ \\
\hline \multicolumn{5}{|l|}{ Gender } \\
\hline Male & $74(49.3)$ & $35(35)$ & $38(44.7)$ & 0.081 \\
\hline Female & $76(50.7)$ & $65(65)$ & $47(55.3)$ & \\
\hline \multicolumn{5}{|l|}{ Marital status } \\
\hline Married & $116(77.3)$ & $75(75)$ & $66(77.6)$ & 0.928 \\
\hline Single & $25(16.7)$ & $17(17)$ & $11(12.9)$ & \\
\hline Divorce & $6(4)$ & $5(5)$ & $6(7.1)$ & \\
\hline Widow & $3(2)$ & $3(3)$ & $2(2.4)$ & \\
\hline \multicolumn{5}{|l|}{ Education level } \\
\hline Below the high school & $7(4.7)$ & $5(5)$ & $4(4.7)$ & 0.546 \\
\hline High school & $46(30.7)$ & $37(37)$ & $33(38.8)$ & \\
\hline Diploma & $26(17.3)$ & $16(16)$ & $21(24.7)$ & \\
\hline Bachelor & $59(39.3)$ & $36(36)$ & $21(24.7)$ & \\
\hline Master degree & $9(6)$ & $3(3)$ & $5(5.9)$ & \\
\hline Doctorate degree & $3(2)$ & $3(3)$ & $1(1.2)$ & \\
\hline \multicolumn{5}{|l|}{ Work status } \\
\hline Yes & $96(64)$ & $46(46)$ & $38(44.7)$ & 0.003 \\
\hline No & $54(36)$ & $54(54)$ & $47(55.3)$ & \\
\hline \multicolumn{5}{|l|}{ BMI categories } \\
\hline Underweight & $2(1.3)$ & $5(5)$ & $2(2.4)$ & 0.001 \\
\hline Normal weight & $50(33.3)$ & $42(42)$ & $27(31.8)$ & \\
\hline Overweight & $65(43.3)$ & $32(32)$ & $39(45.9)$ & \\
\hline Obese & $33(22)$ & $21(21)$ & $17(20)$ & \\
\hline \multicolumn{5}{|l|}{ Duration of suffering of IBD } \\
\hline Duration less than 30 days & - & 29) 29) & $46(54.1)$ & 0.001 \\
\hline Duration from 30-60 days & - & $39) 39)$ & $22(25.9)$ & \\
\hline Duration from 60-90 days & - & $32(32)$ & $17(20)$ & \\
\hline \multicolumn{5}{|c|}{ Family members diagnosed with IBD } \\
\hline Yes & - & $24(24)$ & $13(15.3)$ & 0.001 \\
\hline No & $150(100)$ & $76(76)$ & $72(84.7)$ & \\
\hline \multicolumn{5}{|l|}{ Cigarette Smoking } \\
\hline Yes & $57(38)$ & $25(25)$ & $37(43.5)$ & 0.001 \\
\hline No & $91(60.7)$ & $60(60)$ & $39(45.9)$ & \\
\hline Former-smoker & $2(1.3)$ & $15(15)$ & $9(10.6)$ & \\
\hline \multicolumn{5}{|l|}{ Hookah } \\
\hline Smoker & $36(24)$ & $28(28)$ & $32(37.6)$ & 0.076 \\
\hline Non-Smoker & $108(72)$ & $68(68)$ & $46(54.1)$ & \\
\hline \multicolumn{5}{|l|}{ Working hours/day } \\
\hline$\leq 4$ hours & $131(87.3)$ & $45(45)$ & $4(4.7)$ & 0.001 \\
\hline 4-6 hours & $1(0.7)$ & $1(1)$ & $0(0)$ & \\
\hline$>6-8$ hours & $18(12.0)$ & $54(54)$ & $81(95.3)$ & \\
\hline \multicolumn{5}{|c|}{ Sleep duration hours during week day } \\
\hline Short (4-6 hours) & $54(36)$ & $13(13)$ & $1(1.2)$ & 0.001 \\
\hline Moderate(6-8 hours) & $79(52.7)$ & $81(81)$ & $83(97.6)$ & \\
\hline Long (8-12 hours) & $17(11.3)$ & $6(6)$ & $1(1.2)$ & \\
\hline \multicolumn{5}{|c|}{ Sleep duration hours during weekend } \\
\hline Short (4-6 hours) & $3(2)$ & $1(1)$ & $0(0)$ & 0.001 \\
\hline Moderate(6-8 hours) & $72(49)$ & $68(68)$ & $82(96.5)$ & \\
\hline Long (8-12 hours) & $72(49)$ & $31(31)$ & $3(3.5)$ & \\
\hline
\end{tabular}




\begin{tabular}{lcccc}
\hline Table I (continued) & & & & \\
\hline Physical activity (MET/week) & & & & \\
\hline Inactive (<600 MET/week) & $49(32.7)$ & $3(3)$ & $1(1.2)$ & 0.001 \\
Minimally active & $23(15.3)$ & $11(11)$ & $6(7.1)$ & \\
$\quad$ 600-1499 MET/week) & & & & \\
HEPA active (> 1500 MET/week) & $78(52)$ & $86(86)$ & $78(91.8)$ & \\
\hline Food problem & & & & \\
\hline Yes & $7(4.7)$ & $14(14)$ & $6(7.1)$ & 0.139 \\
No & $143(95.3)$ & $86(86)$ & $79(92.9)$ & \\
\hline
\end{tabular}

CD: Crohn's disease; HEPA: health-enhancing physical activity; IBD: inflammatory bowel diseases; MET: metabolic equivalent; UC: ulcerative colitis.

A significant difference has been found between cases and controls in BMI. No significant differences were detected in marital status, education level, and hookah smoking. However, cigarette smoking, work status, sleeping duration hours during week and weekend days, family members diagnosed with IBD, and physical activity (MET/week) were significantly different in IBD cases compared to the controls.

Table II shows participants' age, anthropometric measurements and degree of malnutrition depending on PGSGA. Average age for UC was $39.8 \pm 11.9$, CD was $41.2 \pm 12.8$, and $41.4 \pm 12.5$ years for controls. Significant differences were found in weight, height, BMI and waist circumference between controls and UC. However, there was no significant difference in these parameters between controls and CD. A significant difference was found in physical activity between UC and controls, also between $\mathrm{CD}$ and control. Nevertheless, there was no significant difference in physical activity between UC and $\mathrm{CD}$. The degree of malnutrition was significantly different as IBD cases compared to the controls. Moderately and severely malnourished percentages were higher in IBD cases than controls.

Table III shows the dietary characteristics of the study participants. Significant differences were found between cases and controls in the number of daily main meal intake, meals skipped daily, number of daily snack meal intake, and fastfood intake. Furthermore, there was a significant difference in vitamin D supplements intake between controls, UC, and $\mathrm{CD}$ with the higher percentage in $\mathrm{CD}$ [n (\%): 5 (3.3), 44 (44), and 55 (64.7), respectively]. On the contrary, no significant difference between case and control groups in vitamin B12 intake was detected.

The associations between lifestyle factors and IBD risk are shown in table IV. Cigarette smoking, daily working hours as well as daily sleep duration hours during working days were the factors that were associated with the risk of IBD. Cigarette smoking showed a significant protective effect [OR, 0.52 (95\% CI: 0.29-0.96)] against IBD. While the increase in working hours ( $>6-8$ hours/day) showed an increase in the risk for about 22 times ( $\mathrm{OR}=22.13$, 95\% CI: 10.35-47.32), daily sleep duration hours during working days was associated negatively $(\mathrm{OR}=0.05,95 \%$ CI: 0.01-4.68) with the risk of IBD.

\section{DISCUSSION}

The findings of this study add to the evidence for the presence of an association between IBD with lifestyle behaviors. Generally, the findings of this case-control study shed light on the relationship between dietary characteristics, lifestyle

Table II. Anthropometric measurements, physical activity levels and degree of malnutrition among the study participants $(\mathrm{n}=335)$.

\begin{tabular}{|c|c|c|c|c|}
\hline Variables & $\begin{array}{c}\text { Control }(\mathrm{n}=150) \\
\text { Mean } \pm \text { SD }\end{array}$ & $\begin{array}{l}\mathrm{UC}(\mathrm{n}=100) \\
\text { Mean } \pm \text { SD }\end{array}$ & $\begin{array}{l}C D(n=85) \\
\text { Mean } \pm \text { SD }\end{array}$ & $\mathrm{p}$ \\
\hline Age (years) & $41.4 \pm 12.5$ & $39.8 \pm 11.9$ & $41.2 \pm 12.8$ & 0.580 \\
\hline Height $(\mathrm{cm})$ & $166.4 \pm 0.1 \mathrm{a}$ & $162.5 \pm 0.1 \mathrm{~b}$ & $168.4 \pm 0.1 \mathrm{a}$ & 0.001 \\
\hline Current body weight $(\mathrm{Kg})$ & $74.8 \pm 13.1 \mathrm{a}$ & $66.9 \pm 11.9 \mathrm{~b}$ & $75.6 \pm 12.8 \mathrm{a}$ & 0.001 \\
\hline Usual body weight $(\mathrm{Kg})$ & $74.3 \pm 12.7 \mathrm{a}$ & $68.6 \pm 12.5 b$ & $77.5 \pm 13.1 \mathrm{a}$ & 0.001 \\
\hline $\operatorname{BMI}\left(\mathrm{kg} / \mathrm{m}^{2}\right)$ & $27.1 \pm 4.4 \mathrm{a}$ & $25.5 \pm 4.9 \mathrm{~b}$ & $26.8 \pm 4.9 \mathrm{a}$ & 0.021 \\
\hline Waist circumference $(\mathrm{cm})$ & $89.04 \pm 9.0 \mathrm{a}$ & $83.9 \pm 9.3 b$ & $89.9 \pm 13.0 \mathrm{a}$ & 0.001 \\
\hline Hip circumference $(\mathrm{cm})$ & $98.5 \pm 9.8$ & $98.1 \pm 10.5$ & $96.0 \pm 10.4$ & 0.177 \\
\hline Physical activity (MET/week) & $2479.4 \pm 296.8 \mathrm{a}$ & $1971.4 \pm 887.6 \mathrm{~b}$ & $1818.8 \pm 887.2 \mathrm{~b}$ & 0.033 \\
\hline \multicolumn{5}{|c|}{ Degree of malnutrition depending on PG-SGA category N(\%) } \\
\hline A (well nourished) & $119(79.3)$ & $33(33)$ & $21(24.7)$ & 0.001 \\
\hline B ( moderately malnourished) & $31(20.7)$ & $52(52)$ & $56(65.5)$ & \\
\hline C (severely malnourished) & $0(0)$ & $15(15)$ & $8(9.4)$ & \\
\hline
\end{tabular}

Data are presented as mean $\pm \mathrm{SD} ; \mathrm{p}<0.05$ considered significant for ANOVA test and chi square; Different three letters $(a, b, c)$ mean that there is a significant difference between the three variables. 
Table III. Dietary characteristics of the study participants $(n=335)$.

\begin{tabular}{lcccc}
\hline Variables & Control $(\mathrm{n}=150)$ & $\mathrm{UC}(\mathrm{n}=100)$ & $\mathrm{CD}(\mathrm{n}=85)$ & $\mathrm{p}$ \\
& $\mathrm{N}(\%)$ & $\mathrm{N}(\%)$ & $\mathrm{N}(\%)$ & \\
\hline Number of meals intake daily & & & & \\
\hline One meal & $2(1.3)$ & $1(1)$ & $0(0)$ & 0.001 \\
Two meal & $75(50)$ & $72(72)$ & $85(100)$ & \\
Three meal & $73(48.7)$ & $27(27)$ & $0(0)$ & \\
\hline Meals skipped daily & & & & \\
\hline Breakfast & $73(46.7)$ & $27(27)$ & $0(0)$ & 0.001 \\
Lunch & $0(0)$ & $0(0)$ & $0(0)$ & \\
Dinner & $39(26)$ & $61(61)$ & $82(96.5)$ & \\
Both breakfast and lunch & $0(0)$ & $0(0)$ & $0(0)$ & \\
Both breakfast and dinner & $36(24)$ & $11(11)$ & $3(3.5)$ & \\
No meals skipped & $2(1.3)$ & $1(1)$ & $0(0)$ & \\
\hline Number of snacks intake daily & & & & \\
\hline One snack & $25(16.7)$ & $3(3)$ & $0(0)$ & 0.001 \\
Two snack & $85(56.7)$ & $84(84)$ & $82(96.5)$ & \\
Three snack & $38(25.3)$ & $12(12)$ & $3(3.5)$ & \\
More than three snack & $2(1.3)$ & $1(1)$ & $0(0)$ & \\
Does not take snacks & $0(0)$ & $0(0)$ & $0(0)$ & \\
\hline Fast food intake & $36(24.2)$ & $34(34)$ & $30(35.3)$ & 0.115 \\
\hline Does not eat fast food & $113(75.8)$ & $66(66)$ & $55(64.7)$ & \\
Less than once per month & $2(1.3)$ & $1(1)$ & $0(0)$ & \\
1-3 times per month & $114(76.0)$ & $83(83)$ & $82(95.5)$ & \\
1-3 times per week & $34(22.7)$ & $15(15)$ & $3(3.5)$ & \\
4-6 times per week & $0(0)$ & $1(1)$ & $1(1)$ & \\
Once daily & $0(0)$ & $0(0)$ & $0(0)$ & \\
\hline Vitamin D supplement & $5(3.3)$ & $44(44)$ & $55(64.7)$ & 0.001 \\
\hline Yes & $145(96.7)$ & $56(56)$ & $30(35.3)$ & \\
No & & & & \\
\hline Vitamin B12 supplement & & & \\
\hline Yes & & & \\
No & & & & \\
\hline
\end{tabular}

For abbreviations see Table I.

factors and the degree of malnutrition in a selected sample of Jordanians adults.

In this study, we found a significant difference between $\mathrm{UC}, \mathrm{CD}$ and controls in BMI. Our results showed that BMI was significantly $(p=0.021)$ lower in UC as compared to CD and controls. Many studies agree with the results found in our study [26-28]. Ghoshal et al. [26] revealed that IBD patients' BMI was lower than that in non-IBD controls. Flores et al. [27] found that BMI was decreased in patients with active UC but not in patients with $\mathrm{CD}$, compared to healthy controls. However, Mendall et al. [28] found that obesity at diagnosis was more common in subjects with CD versus UC which gives evidence that $\mathrm{CD}$ patients have a higher BMI than UC patients which corresponds with our results.

The findings of this study reveal a significant difference in PA between IBD patients and controls. The results showed that both UC and CD have a lower level of PA than controls $(\mathrm{p}=0.033)$. This is in concordance with a study conducted by Hlavaty et al. [5] who states that there is a significant association between lower weekly rates of sports participation and the development of IBD. Additionally, Gatt et al. [29] document that patients with IBD are significantly less physically active after they are diagnosed with IBD as compared to controls. This could be due to the feeling of being tired and sick more frequently than the controls [29].

When coming to the relationship between IBD and smoking, our study found that the percentage of current and former smokers of cigarettes of CD was higher than of UC and controls. The percentage of smoking in CD was about $54 \%$, whereas in UC it was $40 \%$. Cigarette smoking reveals a significant protective association $(\mathrm{OR}=0.52$; 95\%CI: 0.29 $0.96)$ with the risk of IBD. Rosenfeld et al. [30] documented that smoking increased the risk of developing CD but not the risk of UC. The association between smoking and UC was first described by Harries et al. [7], in 1982, who noted a reduced frequency of smokers among patients with UC compared to healthy controls. Cosnes et al. [31] found that early smoking significantly increase the risk of CD [OR 2.0 
Table IV. The Association between lifestyle factors and IBD risk.

\begin{tabular}{|c|c|c|c|}
\hline Lifestyle factor & $\begin{array}{l}\text { Controls } \\
(\mathrm{n}=150)\end{array}$ & $\begin{array}{c}\text { Cases } \\
(\mathrm{n}=185)\end{array}$ & ${ }^{\star} \mathrm{OR}(95 \% \mathrm{CI})$ \\
\hline \multicolumn{4}{|l|}{ Body mass index } \\
\hline Normal weight & 50 & 69 & 1 \\
\hline Underweight & 2 & 7 & $3.99(0.52-30.90)$ \\
\hline Overweight & 65 & 71 & $1.48(0.83-1.46)$ \\
\hline Obese & 33 & 38 & $0.75(0.38-1.49)$ \\
\hline \multicolumn{4}{|l|}{ Cigarette smoking } \\
\hline No & 36 & 60 & 1 \\
\hline Yes & 108 & 114 & $0.52(0.29-0.96)$ \\
\hline \multicolumn{4}{|l|}{ Working hours/day } \\
\hline$\leq 4$ hours & 131 & 49 & 1 \\
\hline 4-6 hours & 1 & 1 & $3.23(0.114-91.69)$ \\
\hline$>6-8$ hours & 18 & 135 & $22.13(10.35-47.32)$ \\
\hline \multicolumn{4}{|c|}{ Sleep duration hours during working day } \\
\hline Short (4-6 hours) & 54 & 14 & 1 \\
\hline $\begin{array}{l}\text { Moderate (6-8 } \\
\text { hours) }\end{array}$ & 79 & 164 & $0.895(0.13-6.42)$ \\
\hline Long (8-12 hours) & 17 & 7 & $0.05(0.01-4.68)$ \\
\hline \multicolumn{4}{|c|}{ Sleep duration hours during weekend } \\
\hline Short (4-6 hours) & 3 & 1 & 1 \\
\hline $\begin{array}{l}\text { Moderate (6-8 } \\
\text { hours) }\end{array}$ & 72 & 150 & $9.02(0.67-121.60)$ \\
\hline Long (8-12 hours) & 72 & 34 & $1.73(0.123-23.39)$ \\
\hline \multicolumn{4}{|l|}{ Fast Food Intake } \\
\hline 1-3 times per week & 114 & 165 & 1 \\
\hline 4-6 times per week & 34 & 18 & $0.41(0.15-1.17)$ \\
\hline \multicolumn{4}{|c|}{ Number of main meals consumed daily } \\
\hline One meal & 2 & 1 & 1 \\
\hline Two meal & 75 & 157 & $2.34(0.16-35.25)$ \\
\hline Three meal & 73 & 27 & $0.31(0.02-4.86)$ \\
\hline \multicolumn{4}{|l|}{ Meals skipped daily } \\
\hline No meals skipped & 2 & 1 & 1 \\
\hline Breakfast & 73 & 27 & $0.34(0.02-5.28)$ \\
\hline Dinner & 39 & 143 & $4.80(0.31-73.79)$ \\
\hline $\begin{array}{l}\text { Both breakfast and } \\
\text { dinner }\end{array}$ & 36 & 14 & $0.46(0.03-7.44)$ \\
\hline
\end{tabular}

${ }^{*} \mathrm{OR}$ is adjusted for age, gender, marital status, education level, work status, monthly income, physical activity, smoking, family history.

(1.65-2.47)]. Additionally, smoking CD patients had a worse course of illness and decrease in the quality of life, were more likely to develop complications, had a higher rate of hospitalizations, a decrease in response to treatments, and had a greater need for surgery [31]. In UC, nicotine has been tested as a therapeutic mediator in the form of chewing gum, patches, and nicotine-based enemas [32], with contradictory findings and diverse efficacy in the induction of remission when compared to placebo and conventional treatments [33]. It is supposed that the protective effect of cigarette smoking in UC is temporary. The relative risk of developing the disease increases after smoking cessation compared to patients who have never smoked [34].
Sleep disturbances were associated with a greater risk of serious adverse health events, economic consequences, and most importantly, increased all-cause mortality [35]. Our study shows that controls have a higher percentage of moderately and long sleeps duration hours than UC and CD patients. Additionally, daily sleep duration hours during working days is associated with a decreased risk $(\mathrm{OR}=0.05,95 \% \mathrm{CI}$ : 0.01 4.68) of IBD. Almedimigh et al [36] found that IBD patients had poorer sleep quality, and an increased use of sleeping pills compared to controls. Furthermore, patients with clinically active IBD have reported significantly worse sleep than patients with inactive disease. In addition, IBD patients in remission with abnormal sleep may be at increased risk for relapse. Sleep deprivation has been linked to have negative effects on immune function. In addition, alterations in sleep patterns can lead to leukocytosis and an increase in natural killer cells, which can lead to increased inflammatory cytokine production [37]. Interestingly, the cytokines implicated in the regulation of the sleep-wake cycle are also involved in the pathogenesis of chronic inflammatory conditions, including IBD [38]. In our study, working hours ( $>6-8$ hours/day) shows an increase in the risk for about 22 times (OR=22.13, 95\%CI: 10.35-47.32). This could be attributed to a stressful work environment, which may increase as the number of hours worked increases.

Malnutrition is a common feature of IBD. Our study found that UC and CD patients have a higher percentage of moderately malnourished (UC 52\%, CD 65.5\%) and severely malnourished (UC 15\%, CD 9.4\%) than controls. Results from a study conducted by Mijač et al. [39] were replicated by our study. The authors of this study found that the prevalence of under-nutrition and severe under-nutrition in patients with active IBD were $25-69.7 \%$ and $1.3-31.6 \%$, respectively. However, they did not detect any abnormalities among the controls. Also, Nguyen et al. [13] findings go hand in hand with our results. The researchers found that the prevalence of malnutrition was greater in CD and UC patients than non-IBD patients $(6.1 \%$ and $7.2 \%$ versus $1.8 \%, \mathrm{p}<0.0001)$ [13].

Further results from this study, show that the percentage of fast-food intake per month for UC and CD is higher than controls (83\% UC; $95.5 \%$ CD; and 76\% controls). Similar results by Niewiadomski et al. [40] were documented. The researchers of this study found that an increased relative risk of developing IBD has also been associated with frequent intake of fast foods (fast foods are high in trans-unsaturated fatty acids).

Additionally, our study found that controls have a higher percentage of eating three meals per day than UC and CD patients. Pieczynska et al. [41] results are consistent with our study. They found that more than $47 \%$ of CD patients and $46 \%$ of UC patients ate less than three meals per day [41]. This was due to the symptoms that IBD patients suffer from which includes bloating, diarrhea, abdominal pain and cramps. Almost all of these symptoms may lead to appetite loss and consequently a reduction in the number of meals eaten daily [41].

In regard to vitamin $\mathrm{D}$, our study found that $\mathrm{UC}$ and CD patients have a higher percentage of vitamin $\mathrm{D}$ intake supplements than controls (UC 44\%, CD 64.7\%, controls $3.3 \%$ ). Low serum vitamin $\mathrm{D}$ was found to be associated with increased disease activity, inflammation, and clinical relapse [42]. Ghishan et al. [43] findings agree with our study. They 
revealed that IBD patients took vitamin D supplements more than controls to help in enhancing bone mineral density in IBD patients and to reduce disease activity [43]. Another study by Yang et al. [44] documents that long-term, high doses of vitamin $\mathrm{D}$ supplementation significantly reduce the disease score in active IBD.

In our study confounders that may affect the development of IBD including stress, genetic factor and other health states, were not estimated. Furthermore, our sample size was small in comparison to other studies, despite it being enough to draw findings about our patients. This small sample size was due to financial and time constraints.

\section{CONCLUSIONS}

The present study provides evidence supporting the presence of an association between lifestyle factors and the risk of IBD. Higher BMI and physical activity (MET/week) values were found in controls compared to cases. Cigarette smoking, work status, sleeping duration hours during week and weekend day, the number of daily main meal intake, meals skipped daily, number of daily snack meal intake, and fast-food intake were significantly different in IBD cases compared to the controls.

Conflicts of interest: None to declare.

Authors' contributions: R.F.T and Y.M.R. conceived the study. T.R.Q. collected the data and performed statistical analysis. R.F.T., T.R.Q. and Y.M.R. interpreted results and drafted the manuscript. All authors drafted the manuscript and approved it.

Acknowledgements: This research was funded by the Deanship of Academic Research of the University of Jordan. The authors would like to thank Dr Sabika Allehdan for her help in data entry and analysis.

\section{REFERENCES}

1. Vagianos K, Bector S, McConnell J, Bernstein CN. Nutrition assessment of patients with inflammatory bowel disease.J. Parenter Enter Nutr 2007;31:311-319. doi:10.1177/0148607107031004311

2. Ghanma AM, Ghanama RA, Hijazeen RI. Clinical presentations of inflammatory bowel disease (IBD) among children at King Hussein Medical Center (KHMC) in Amman/Jordan. Pakistan J Med Health Sci 2012;6:279-282.

3. Ye Y, Pang Z, Chen W, Ju S, Zhou C. The epidemiology and risk factors of inflammatory bowel disease. Int J Clin Exp Med 2015;8:22529-22542.

4. Ng SC, Tang W, Leong RW, et al. Environmental risk factors in inflammatory bowel disease: a population-based case-control study in Asia-Pacific. Gut 2015;64:1063-1071. doi:10.1136/gutjnl-2014-307410

5. Hlavaty T, Toth J, Koller T, et al. Smoking, breastfeeding, physical inactivity, contact with animals, and size of the family influence the risk of inflammatory bowel disease: A Slovak casecontrol study. United European Gastroenterol J 2013;1:109-119. doi:10.1177/2050640613478011

6. Chan SS, Luben R, Olsen A, et al. Body Mass Index and the Risk for Crohn's Disease and Ulcerative Colitis: Data From a European Prospective Cohort Study (The IBD in EPIC Study). Am J Gastroenterol 2013;108:575-582. doi:10.1038/ajg.2012.453
7. Harries AD, Baird A, Rhodes J. Non-smoking: a feature of ulcerative colitis. Br Med J (Clin Res Ed) 1982;284:706. doi:10.1136/ bmj.284.6317.706

8. Legaki E, Gazouli M. Influence of environmental factors in the development of inflammatory bowel diseases. World J Gastrointest Pharmacol Ther 2016;7:112-125. doi:10.4292/wjgpt.v7.i1.112

9. Nos P, Domènech E. Management of Crohn's disease in smokers: Is an alternative approach necessary? World J Gastroenterol 2011;17:35673574. doi:10.3748/wjg.v17.i31.3567

10. Cosnes J. Smoking, physical activity, nutrition and lifestyle: environmental factors and their impact on IBD. Dig Dis 2010;28:411417. doi:10.1159/000320395

11. Bitton A, Dobkin PL, Edwardes MD, et al. Predicting relapse in Crohn's disease: a biopsychosocial model. Gut 2008;57:1386-1392. doi:10.1136/ gut.2007.134817

12. Goh J, O'Morain CA. Nutrition and adult inflammatory bowel disease. Aliment Pharmacol Ther 2003;17:307-320. doi:10.1046/j.13652036.2003.01482.x

13. Nguyen GC, Munsell M, Harris ML. Nationwide prevalence and prognostic significance of clinically diagnosable proteincalorie malnutrition in hospitalized inflammatory bowel disease patients. Inflamm. Bowel Dis 2008;14:1105-1111. doi:10.1002/ibd.20429

14. Loddo I, Romano C. Inflammatory bowel disease: genetics, epigenetics, and pathogenesis. Front Immunol 2015;6:551. doi:10.3389/ fimmu.2015.00551

15. Ghazzawe E, Al-Mrayat Z. Review of chronic ulcerative colitis cases at King Hussein Medical Centre, Jordan. East Mediterr Health J 2007;13:249-300.

16. Sallis JF, Haskell WL, Wood PD, et al. Physical activity assessment methodology in the Five-City Project. Am J Epidemiol 1985;121:91-106. doi:10.1093/oxfordjournals.aje.a113987

17. Jetté M, Sidney K, Blümchen G. Metabolic equivalents (METS) in exercise testing, exercise prescription, and evaluation of functional capacity. Clin Cardiol 1990;13:555-565. doi:10.1002/clc.4960130809

18. McMahan LA. Physical Activity Levels of College Freshman: Comparison of Surveys with Objective Measures of Physical Activity. Master Thesis. University of Tennessee, 2007. Available at: https://trace. tennessee.edu/utk_gradthes/310/

19. Craig CL, Marshall AL, Sjöström M, et al. International physical activity questionnaire: 12-country reliability and validity. Med Sci Sports Exerc 2003;35:1381-1395. doi:10.1249/01.MSS.0000078924.61453.FB

20. de la Torre MV, Stein K, Garibay EV, et al. Patient-Generated Subjective Glob Assessment of nutritional status in pediatric patients with recent cancer diagnosis. Nutr Hosp 2017;34:1050-1058. doi:10.20960/nh.935

21. Lee RD, Nieman DC. Nutritional Assessment. 3rd Edition. Boston: McGraw-Hill, 2003.

22. Abalkhail B, Shawky S. Comparison between body mass index, triceps skin fold thickness and mid-arm muscle circumference in Saudi adolescents. Ann Saudi Med 2002;22: 324-328. doi:10.5144/02564947.2002.324

23. Jackson AS, Pollock ML. Generalized equations for predicting body density of men. Br J Nutr1978;49:497-504. doi:10.1079/bjn19780152

24. Jackson AS, Pollock ML, Ward A. Generalized equations for predicting body density of women. Med Sci Sports Exerc 1980;12:175-182.

25. Siri WE. The gross composition of the body. Adv Biol Med Phys 1956;4:239-280. doi:10.1016/b978-1-4832-3110-5.50011-x

26. Ghoshal UC, Shukla A. Malnutrition in inflammatory bowel disease patients in northern India: frequency and factors influencing its development. Trop Gastroenterol 2008;29:95-97. 
27. Flores A, Burstein E, Cipher DJ, Feagins LA. Obesity in inflammatory bowel disease: a marker of less severe disease. Dig Dis Sci 2015;60:24362445. doi:10.1007/s10620-015-3629-5

28. Mendall MA, Gunasekera AV, John BJ, Kumar D. Is obesity a risk factor for Crohn's disease? Dig Dis Sci 2011;56:837-844. doi:10.1007/s10620010-1541-6

29. Gatt K, Schembri J, Katsanos KH, et al. Inflammatory bowel disease [IBD] and physical activity: a study on the impact of diagnosis on the level of exercise amongst patients with IBD. J Crohns Colitis 2019;13:686-692. doi:10.1093/ecco-jcc/jjy214

30. Rosenfeld G, Bressler B. The truth about cigarette smoking and the risk of inflammatory bowel disease. Am J Gastroenterol 2012;107:14071408. doi:10.1038/ajg.2012.190

31. Cosnes J, Carbonnel F, Carrat F, Beaugerie L, Cattan S, Gendre J. Effects of current and former cigarette smoking on the clinical course of Crohn's disease. Aliment Pharmacol Ther 1999;13:1403-1411. doi:10.1046/j.1365-2036.1999.00630.x

32. Ingram JR, Thomas GA, Rhodes J, et al. A randomized trial of nicotine enemas for active ulcerative colitis. Clin Gastroenterol Hepatol 2005;3:1107-1114. doi:10.1016/s1542-3565(05)00849-9

33. McGrath J, McDonald JWD, MacDonald JK. Transdermal nicotine for induction of remission in ulcerative colitis. Cochrane Database Syst Rev 2004;(4):CD004722. doi:10.1002/14651858.CD004722.pub2

34. Calkins BM. A meta-analysis of the role of smoking in inflammatory bowel disease. Dig Dis Sci 1989;34:1841-1854. doi:10.1007/ BF01536701

35. Kinnucan JA, Rubin DT, Ali T. Sleep and inflammatory bowel disease: exploring the relationship between sleep disturbances and inflammation. Gastroenterol Hepatol 2013;9:718-727.
36. Almedimigh A, Szeto S, Dave J, Alsulaimi N, Myint A, Borum ML. P108 sleep disorders in inflammatory bowel disease: The forgotten discussion. Inflamm Bowel Dis 2018;24 (suppl 1):S39. doi:10.1093/ibd/ izy019.120

37. Ranjbaran Z, Keefer L, Stepanski E, Farhadi A, Keshavarzian A. The relevance of sleep abnormalities to chronic inflammatory conditions. Inflamm Res 2007;56:51-57. doi:10.1007/s00011-006-6067-1

38. Gamaldo CE, Shaikh AK, McArthur JC. The sleep-immunity relationship. Neurol Clin 2012;30:1313-1343. doi:10.1016/j.ncl.2012.08.007

39. Mijac DD, Janković GL, Jorga J, Krstić MN. Nutritional status in patients with active inflammatory bowel disease: prevalence of malnutrition and methods for routine nutritional assessment. Eur J Intern Med 2010;21:315-319. doi:10.1016/j.ejim.2010.04.012

40. Niewiadomski O, Studd C, Wilson J, et al. Influence of food and lifestyle on the risk of developing inflammatory bowel disease. Intern Med J 2016;46:669-676. doi:10.1111/imj.13094

41. Pieczynska J, Prescha A, Ilow R, et al. Dietary habits of patients with inflammatory bowel disease-a short report. POL J Food Nutr Sci 2009;59:91-93.

42. Garg M, Rosella O, Lubel JS, Gibson PR. Association of circulating vitamin $\mathrm{D}$ concentrations with intestinal but not systemic inflammation in inflammatory bowel disease. Inflamm Bowel Dis 2013;19:26342643. doi:10.1097/01.MIB.0000436957.77533.b2

43. Ghishan FK, Kiela PR. Vitamins and minerals in inflammatory bowe disease. Gastroenterol Clin North Am 2017;46:797-808. doi:10.1016/j. gtc.2017.08.011

44. Yang L, Weaver V, Smith JP, Bingaman S, Hartman TJ, Cantorna MT. Therapeutic effect of vitamin d supplementation in a pilot study of Crohn's patients. Clin Transl Gastroenterol 2013;4:e33. doi:10.1038/ctg.2013.1 